\title{
Estimating Sex from second and seventh cervical vertebras in Iranian adult population using Computed Tomography scan images
}

\section{Reza Saadat Mostafavi}

iran university of meical sciences

\section{Azadeh Memarian}

iran university of medical sciences

Arezoo Amiri ( $\nabla$ arezooamiri@protonmail.com )

Omid Motamedi

iran university of medical sciences

\section{Research note}

Keywords: Cervical vertebrae, Computer Tomography, Dimension, Metric, Sex

Posted Date: May 17th, 2020

DOI: https://doi.org/10.21203/rs.3.rs-26554/v1

License: (c) (1) This work is licensed under a Creative Commons Attribution 4.0 International License. Read Full License 


\section{Abstract}

Objectives The study aimed to estimating the sex from several metric dimensions of second and seventh cervical vertebras using Computed Tomography (CT) scan images of a series of Iranian adult populations. In this study, sexual dimorphism of 15 indexes of second cervical vertebra and 10 indexes of the seventh cervical vertebra were investigated. Indexes were obtained from CT scan images of 70 patients who underwent CT scan imaging for other indications.

Results Among measured dimensions of the second vertebra, 9 were associated with sex. Of these indexes, Maximum width of the superior Facet and Maximum height of axis were independent predictors of sex with correct sex classification of $81.4 \%$ when used in combination. Four of 10 seventh vertebra's indexes were associated with sex: Length of superior facets, Length of the inferior surface of the vertebral body, Width of the inferior surface of the vertebral body, and the Length of spinous process. Length of the inferior surface of the vertebral body and the Length of spinous process were independent sex predictors and together provided sex classification accuracy of $78.6 \%$. We found considerable accuracy in sex classification by using metric dimensions of second and seventh cervical vertebras in the Iranian adult population.

\section{Introduction}

Reliable estimation of sex from human skeletal remains is one of the most important factors in biological profiling and forensic anthropology casework, especially in cases of mass disaster and high-intensity explosions [1-7]. The biological profile indices including age at death, stature, and ancestry are sexdependent which are affected by sex estimation as a primary significance $[1,4,8]$. Several sex determination studies have been conducted by metric analysis of talus, femur, patella, humerus, calcaneus, metatarsals, tarsals, metacarpals, phalanges, scapula, clavicle, and sternum [9-17]. Other studies applied CT imaging and real bone subjects with different sample sizes and levels of accuracy for sex discrimination from the vertebra [3, 18-23]. Voisin et al. showed that the useful sexually dimorphic bones for forensic sex estimation are the first seven cervical vertebrae (C1-C7) [24]. Forensic medicine has been revolutionized using modern cross-sectional imaging techniques including 3D imaging techniques such as computed tomography (CT) and magnetic resonance imaging (MRI) over the past decade [7]. These methods could be useful in visualizing almost every anatomical and pathological structure with high resolution and quality [25].

The aim of the current study was focus on the level of sexual accuracy in the second and seventh cervical vertebrae to establish an accurate sex estimation method using measurement data obtained from the CT scan imaging of Iranian skeletal populations.

\section{Material And Methods}

\section{Study Design and Participants}


This cross-sectional study was carried out on sexuality accuracy of several metric dimensions of second and seventh cervical vertebrae using CT scan imaging of a series of Iranian adult population. Seventy cases (35 females and 35 males) aged 18 and above, who have undergone imaging for other reasons in Hazrat-Rasool Hospital were selected. All cases were selected via multi-level cluster random sampling.

\section{Inclusion and Exclusion Criteria}

Patients who were $\geq 18$-year old age and underwent CT imaging according to their physician's advice were included in this study. Cases under the age of and who had a history of the following disorders were excluded from the study:

- History of neck trauma with any severity

- Having structural or anatomical abnormalities in the neck area

- History of rheumatologic disorders with neck involvement

- History of any type of surgery, regenerative or therapeutic intervention in the neck area

\section{Statistical Analysis}

The collected data were analyzed using the SPSS version 21. To test the relationship between qualitative variables, Chi-squared test was used. Quantitative variables were compared between the two groups by Ttest. Pearson correlation test was used to examine the relationship between quantitative variables such as age and dimensions of vertebrae. Logistic Regression Model was applied to determine the independent predictor variables of gender and was selected as the reference in female gender regression. Statistically significant level was $<0.05$.

\section{Data Collection}

The following indices of second and seventh cervical vertebrae were measured to determine sexual dimorphism using CT scan imaging of the cases.

\section{The 15 indices of second cervical vertebra:}

1. Max height of the axis (AMA): measured as sagittal view

2. Max length of the axis (CMA): measured as sagittal view

3. Odontoid process sagittal diameter (DSD): measured as axial view

4. Odontoid process transverse diameter (DTD): measured as axial view

5. Max distance between the superior facets (DMFS): measured as coronal view

6. Max length of the sup. Facet (CMFS): measured as sagittal view

7. Max width of sup. Facet (LMFS): measured as coronal view

8. Length of the vertebral foramen (CMFV): measured as axial view

9. Sagittal max body diameter (DSMC): measured as sagittal view 
10. Max width of the vertebral foramen (LMFV): measured as axial view

11. Max height of the odontoid process (AMD): measured as coronal view

12. Max transvers diameter of the body (DTMC): measured as coronal view

13. Max width of the axis (LMA): measured as coronal view

14. Max length of the inf. Facet (CMFI): measured as sagittal view

15. Max width of the inf. Facet (LMFI): measured as coronal view

\section{The 10 indices of the seventh cervical vertebra:}

1. Length of the sup. Facet (LSF): measured as sagittal view

2. Width of the sup. Facets (WSF): measured as coronal view

3. Length of the inf. Facets (LIF): measured as sagittal view

4. Width of the inf. Facets (WIF): measured as coronal view

5. Length of the vertebral foramen (LVF): measured as axial view

6. Width of the vertebral foramen (WVF): measured as axial view

7. Length of the inf. surface of the vertebral body (LVB): measured as sagittal view

8. Width of the inf. surface of the vertebral body (WVB): measured as coronal view

9. Length of spinous process (LSP): measured as axial view

10. Height of spinous process (HSP): measured as sagittal view

\section{Results}

A total of 70 cases ( 35 females and 35 males) with the mean age of $40.91 \pm 14.85$ years (18-82) participated in this study. Data showed that there is no significant difference between male and female groups in this study ( $p$-value $=0.8$ ). The characteristics of the 10 and 15 indices of each cervical vertebra in the whole population are described in Tables 1. A total of 9 out of 15 indices measured in the second cervical vertebra were significantly different in males and females ( $p$-value < 0.05). The AMA, LMA, DSD, DMFS, CMSF, LMFS, AMD, DSMC, and LMFI indices were significantly higher in males than in females Table 2. Four out of 10 indices measured in the seventh cervical vertebra were significantly different in males and females ( $p$-value $<0.05)$. The LSF, LIVB, WIVB and LSP indices were significantly higher in men than in women Table 2. 
Table 1

The characteristics of the 15 indices of the second cervical vertebra and 10 indices of the seventh cervical vertebra in the whole population

\begin{tabular}{|c|c|c|c|}
\hline Indices & Mean \pm SD & Minimum & Maximum \\
\hline \multicolumn{4}{|c|}{15 indices of the second cervical vertebra } \\
\hline AMA & $37.93 \pm 3.68$ & 52 & 30 \\
\hline CMA & $48.5 \pm 3.76$ & 58 & 39 \\
\hline LMA & $53.47 \pm 4.98$ & 70 & 43 \\
\hline DSD & $10.79 \pm 1.03$ & 14 & 9 \\
\hline DTD & $9.50 \pm 0.90$ & 12 & 7 \\
\hline DMFS & $44.29 \pm 3.07$ & 54 & 36 \\
\hline CMFS & $13.26 \pm 1.62$ & 17 & 9 \\
\hline LMFS & $13.84 \pm 1.47$ & 17 & 10 \\
\hline CMFV & $17.69 \pm 1.40$ & 21 & 15 \\
\hline LMFV & $23.76 \pm 1.93$ & 28 & 20 \\
\hline AMD & $16.19 \pm 1.86$ & 20 & 12 \\
\hline DSMC & $15.34 \pm 1.62$ & 20 & 11 \\
\hline DTMC & $18.70 \pm 1.77$ & 25 & 15 \\
\hline CMFI & $10.04 \pm 1.23$ & 12 & 7 \\
\hline LMFI & $10.53 \pm 1.24$ & 13 & 8 \\
\hline \multicolumn{4}{|c|}{10 indices of the seventh cervical vertebra } \\
\hline LSV & $91 \pm 1.18$ & 12 & 7 \\
\hline WSF & $12.13 \pm 1.21$ & 15 & 9 \\
\hline LIF & $9.57 \pm 1.20$ & 13 & 7 \\
\hline WIF & $12.17 \pm 1.50$ & 15 & 8 \\
\hline LVF & $15.27 \pm 1.96$ & 24 & 13 \\
\hline WVF & $24.79 \pm 1.85$ & 30 & 22 \\
\hline LIVB & $16.33 \pm 1.88$ & 21 & 12 \\
\hline WIVB & $25.79 \pm 2.59$ & 33 & 21 \\
\hline LSP & $23.99 \pm 3.98$ & 33 & 14 \\
\hline
\end{tabular}




\begin{tabular}{|llll|}
\hline Indices & Mean \pm SD & Minimum & Maximum \\
\hline HSP & $7.80 \pm 14.10$ & 11 & 5 \\
\hline
\end{tabular}


Table 2

Comparison of 15 indices related to second cervical vertebra and 10 indices related to seventh cervical vertebra between sex

\begin{tabular}{|c|c|c|c|c|c|}
\hline Indices & Gender & Mean \pm SD & Minimum & Maximum & p-value \\
\hline \multicolumn{6}{|c|}{15 indices related to second cervical vertebra } \\
\hline \multirow[t]{2}{*}{ AMA } & Male & $39.57 \pm 3.92$ & 31 & 52 & \multirow[t]{2}{*}{$<0.001$} \\
\hline & Female & $36.29 \pm 2.53$ & 30 & 40 & \\
\hline \multirow[t]{2}{*}{ CMA } & Male & $49.97 \pm 3.53$ & 42 & 58 & \multirow[t]{2}{*}{0.30} \\
\hline & Female & $47.06 \pm 3.43$ & 39 & 56 & \\
\hline \multirow[t]{2}{*}{ LMA } & Male & $55.14 \pm 3.90$ & 46 & 63 & \multirow[t]{2}{*}{0.004} \\
\hline & Female & $51.80 \pm 5.42$ & 43 & 70 & \\
\hline \multirow[t]{2}{*}{ DSD } & Male & $11.17 \pm 1.07$ & 9 & 14 & \multirow[t]{2}{*}{0.001} \\
\hline & Female & $10.40 \pm 0.85$ & 9 & 12 & \\
\hline \multirow[t]{2}{*}{ DTD } & Male & $9.63 \pm 0.91$ & 7 & 11 & \multirow[t]{2}{*}{0.23} \\
\hline & Female & $9.37 \pm 0.88$ & 8 & 12 & \\
\hline \multirow[t]{2}{*}{ DMFS } & Male & $45.11 \pm 2.27$ & 40 & 50 & \multirow[t]{2}{*}{0.02} \\
\hline & Female & $43.46 \pm 3.54$ & 36 & 54 & \\
\hline \multirow[t]{2}{*}{ CMFS } & Male & $13.66 \pm 1.53$ & 10 & 16 & \multirow[t]{2}{*}{0.04} \\
\hline & Female & $12.86 \pm 1.63$ & 9 & 17 & \\
\hline \multirow[t]{2}{*}{ LMFS } & Male & $14.51 \pm 1.29$ & 11 & 17 & \multirow[t]{2}{*}{$<0.001$} \\
\hline & Female & $13.17 \pm 1.34$ & 10 & 16 & \\
\hline \multirow[t]{2}{*}{ CMFV } & Male & $17.97 \pm 1.50$ & 15 & 20 & \multirow[t]{2}{*}{0.09} \\
\hline & Female & $17.40 \pm 1.24$ & 15 & 21 & \\
\hline \multirow[t]{2}{*}{ LMFV } & Male & $24.17 \pm 2.06$ & 20 & 28 & \multirow[t]{2}{*}{0.07} \\
\hline & Female & $23.34 \pm 1.71$ & 20 & 27 & \\
\hline \multirow[t]{2}{*}{ AMD } & Male & $16.69 \pm 2.04$ & 13 & 20 & \multirow[t]{2}{*}{0.02} \\
\hline & Female & $15.69 \pm 1.51$ & 12 & 19 & \\
\hline \multirow[t]{2}{*}{ DSMC } & Male & $16.14 \pm 1.37$ & 14 & 20 & \multirow[t]{2}{*}{$<0.001$} \\
\hline & Female & $14.54 \pm 1.46$ & 11 & 19 & \\
\hline DTMC & Male & $19.11 \pm 1.73$ & 17 & 25 & 0.05 \\
\hline
\end{tabular}




\begin{tabular}{|c|c|c|c|c|c|}
\hline Indices & Gender & Mean \pm SD & Minimum & Maximum & $p$-value \\
\hline & Female & $18.29 \pm 1.74$ & 15 & 22 & \\
\hline \multirow[t]{2}{*}{ CMFI } & Male & $10.20 \pm 1.02$ & 8 & 12 & \multirow[t]{2}{*}{0.29} \\
\hline & Female & $9.89 \pm 1.41$ & 7 & 12 & \\
\hline \multirow[t]{2}{*}{ LMFI } & Male & $10.94 \pm 1.26$ & 9 & 13 & \multirow[t]{2}{*}{0.004} \\
\hline & Female & $10.11 \pm 1.08$ & 8 & 13 & \\
\hline \multicolumn{6}{|c|}{10 indices related to seventh cervical vertebra } \\
\hline \multirow[t]{2}{*}{ LSV } & Male & $9.49 \pm 1.09$ & 12 & 7 & \multirow[t]{2}{*}{0.005} \\
\hline & Female & $8.71 \pm 1.15$ & 12 & 7 & \\
\hline \multirow[t]{2}{*}{ WSF } & Male & $12.40 \pm 1.17$ & 15 & 9 & \\
\hline & Female & $11.86 \pm 1.22$ & 14 & 9 & \\
\hline \multirow[t]{2}{*}{ LIF } & Male & $9.77 \pm 1.21$ & 12 & 8 & \multirow[t]{2}{*}{0.16} \\
\hline & Female & $9.37 \pm 1.17$ & 13 & 7 & \\
\hline \multirow[t]{2}{*}{ WIF } & Male & $12.46 \pm 1.24$ & 15 & 10 & \multirow[t]{2}{*}{0.11} \\
\hline & Female & $11.89 \pm 1.69$ & 15 & 8 & \\
\hline \multirow[t]{2}{*}{ LVF } & Male & $15.66 \pm 2.21$ & 24 & 13 & \multirow[t]{2}{*}{0.10} \\
\hline & Female & $14.89 \pm 1.62$ & 19 & 13 & \\
\hline \multirow[t]{2}{*}{ WVF } & Male & $24.94 \pm 1.71$ & 30 & 22 & \multirow[t]{2}{*}{0.48} \\
\hline & Female & $24.63 \pm 1.99$ & 29 & 22 & \\
\hline \multirow[t]{2}{*}{ LIVB } & Male & $17.17 \pm 1.76$ & 21 & 13 & \multirow[t]{2}{*}{$<0.001$} \\
\hline & Female & $15.49 \pm 1.62$ & 21 & 12 & \\
\hline \multirow[t]{2}{*}{ WIVB } & Male & $26.63 \pm 3.06$ & 33 & 21 & \multirow[t]{2}{*}{0.006} \\
\hline & Female & $24.94 \pm 1.66$ & 27 & 21 & \\
\hline \multirow[t]{2}{*}{ LSP } & Male & $26.03 \pm 3.51$ & 33 & 20 & \multirow[t]{2}{*}{$<0.001$} \\
\hline & Female & $24.94 \pm 1.66$ & 28 & 14 & \\
\hline \multirow[t]{2}{*}{ HSP } & Male & $8.11 \pm 1.47$ & 11 & 5 & \multirow[t]{2}{*}{0.06} \\
\hline & Female & $7.49 \pm 1.29$ & 10 & 5 & \\
\hline
\end{tabular}

Regarding the relationship between a number of dimensions belong to each vertebra and gender, logistic regression was used to determine the independent predictive dimensions of sex in each vertebrate. The 
cases that were statistically significant with sex in Tables 2 were included in the logistic regression model. In order to predict the dependent variable of sex based on the dimensions of each vertebrate, the results of the Logistic regression are summarized in Tables 4 . The reference point for logistic regression is the female sex.

The AMA and LMFS variables determined as the independent predictors of sex in the second cervical vertebra. The mentioned two variables, along with each other, had a diagnostic accuracy of $81.4 \%(82.9 \%$ for women and $80 \%$ for men) (Table 3). The LIVB and LSP variables considered as the independent predictors of sex in second cervical vertebra. The mentioned two variables, along with each other, had a diagnostic accuracy of $78.6 \%$ ( $80 \%$ for women and $77.1 \%$ for men) (Supplement). In order to evaluate the relationship between age and indices and due to the normal distribution of data, Pearson correlation test was used in the whole population and each sex (Supplement).

Table 3

The Logistic regression model to determine the predictive indices of sex in the second cervical vertebra

\begin{tabular}{|c|c|c|c|c|}
\hline \multirow[t]{2}{*}{ Dimensions of second cervical vertebra } & \multicolumn{2}{|c|}{$95 \%$ confidence interval } & \multirow[t]{2}{*}{ Odds ratio } & \multirow[t]{2}{*}{ B } \\
\hline & Upper limit & Lower limit & & \\
\hline AMA & 2.046 & 1.051 & 1.466 & 0.383 \\
\hline LMA & 1.178 & 0.838 & 0.994 & -.006 \\
\hline DSD & 3.235 & 0.598 & 1.391 & 0.330 \\
\hline DMFS & 1.304 & 0.776 & 1.006 & .006 \\
\hline CMFS & 1.376 & 0.519 & 0.845 & -0.169 \\
\hline LMFS & 3.454 & 1.153 & 1.996 & 0.691 \\
\hline AMD & 1.435 & 0.500 & 0.847 & -0.166 \\
\hline DSMC & 2.549 & 0.786 & 1.415 & 0.347 \\
\hline LMFI & 2.725 & 0.723 & 1.404 & 0.339 \\
\hline
\end{tabular}

Only DMFS, DSMC, and CMFI indices of the second vertebra showed a slight correlation coefficient and positive significant correlation with age. There was no significant correlation between age and second vertebra indices in males. There was also a significant positive and moderate correlation between age in females and CMA, LMA, DTD, DMFS, CMFS indices. Only the LSF and LIVB indices of the seventh cervical vertebra had a slightly significant and positive correlation with age. Evaluation of correlation between age and the seventh vertebra indices showed that WIF had reverse and moderate correlation with age and HSP had a moderate and positive correlation with age. In the correlation analysis between the seventh indices with age in females, LIVB and WIVB showed a significant positive and moderate correlation. 


\section{Discussion}

Findings of the second cervical vertebra indices in males and females showed that in all cases, the dimensions of collected indices from the vertebrae of males are greater than that of females, but in 9 out of 15 indices, this difference was statistically significant. These 9 indices were including AMA, LMA, DSD, DMFS, CMFS, LMFS, AMD, DSMC, and LMFI. Among the 9 variables which had a significant correlation with sex, 2 variables of LMSF and AMA considered as the independent predictive of sex with an odds ratio of 2 and 1.47, respectively and they had diagnostic accuracy of $81.4 \%$. This indicates the presence of sexual dimorphism in the measurements of the Iranian vertebrae. The most significant mean difference was found in the linear dimensions of the second vertebra of LMA and AMA between the two sexes.

In a study on the cervical vertebra of skeletal specimens, the 15 linear indices of cervical vertebra were examined, which were largely in accordance with the metric dimensions measured in our study [1]. The size of the examined dimensions was slightly different from the dimensions of our study [1]. In all cases, dimensions were higher in males, but the LMA and DSMC indices had the most difference between the two sexes [1]. In their study, four indices including CMA, LMA, LMFSD, and DSMC were independent predictors of sex with a predictive accuracy of $87 \%$ between sexes [1]. In another study by Marlow et al., 9 indices of cervical vertebra dimensions were measured, some of these dimensions are similar to those measured in our study. All of these dimensions in males were significantly larger than females [3]. Of these dimensions, XSL, SFS, SFT, LVF, and XDH were sex-independent predictors that provided a total of $77 \%$ sex diagnostic accuracy [3].

In comparison of our study with the above-mentioned studies on second cervical vertebral indices, a few points were noted: First, in all of the mentioned cases, as well as our study, the upper fast was considered as an independent predictor of sex; Second, the diagnostic accuracy of sex determination in different dimensions was significant in all cases; Third, although all dimensions were larger in males than females, but the mean difference was low even in significant indices suggesting that it is essential to be more focused on practical points of these low rates of mean difference.

In terms of a seventh cervical vertebra of current study, the 10 linear indices were investigated. All dimensions in this vertebra were higher in males than in females, and statistically significant correlations with sex were observed in 4 indices including the LSF, LIVB, WIVB, and LSP. Of these four indices, only two variables LIVB and LSP were independent sex predictors. The two variables had a diagnostic accuracy of $78.6 \%$. In confirmation of the findings of the current study, assessment of the seventh cervical vertebra dimensions amongst the three groups of whites, blacks, and South Africa tribes showed that the anterior posterior's length, width and height of the vertebra were greater in males than females [26].

Studies have shown that the dimensions of the cervical vertebrae are correlated with skeletal dimensions and the larger dimensions of the skeletal vertebrae in males are attributed to the larger body size of them [27]. However, in this study, both the dimensions of the vertebral bodies and their posterior pectorals were statistically significant with sex. In the present study, relationships between age and dimensions of the 
vertebrae were observed. Correlation between age and cervical vertebral dimensions was mostly positive and weak. Considering the age range of the population was under the 69 year, the possibility of degenerative changes in the vertebra should be considered, which affects the dimensions of the vertebra. Other studies have shown the relationship between age and dimensions of cervical vertebra $[4,28]$.

All dimensions measured for the second and seventh cervical vertebrae were higher in men than women in this study. The height of the second vertebra and the transverse diameter of the upper fast were independent sex predictors, with an accuracy of $81.4 \%$. In the seventh vertebra, the anterior-posterior of the vertebral body and the posterior length of the vertebra were independent predictors of sex, which had an accuracy of $78.6 \%$ in sex determination. The results of this study showed a high accuracy of cervical vertebral dimensions in sex determination of skeletal remains in the Iranian population.

\section{Limitation}

It is better the study perform with a larger sample population.

\section{Abbreviations}

\section{CT}

Computed Tomography; AMA:Max height of the axis; CMA:Max length of the axis; DSD:Odontoid process sagittal diameter; DTD:Odontoid process transverse diameter; DMFS:Max distance between the superior facets; CMFS:Max length of the sup. Facet; LMFS:Max width of sup. Facet; CMFV:Length of the vertebral foramen; DSMC:Sagittal max body diameter; LMFV:Max width of the vertebral foramen; AMD:Max height of the odontoid process; DTMC:Max transvers diameter of the body; LMA:Max width of the axis; CMFI:Max length of the inf. Facet; LMFI:Max width of the inf. Facet; LSF:Length of the sup. Facet; WSF:Width of the sup. Facets; LIF:Length of the inf. Facets; WVF:Width of the inf. Facets; LVF:Length of the vertebral foramen; WVF:Width of the vertebral foramen; LVB:Length of the inf. surface of the vertebral body; WVB:Width of the inf. surface of the vertebral body; LSP:Length of spinous process; HSP:Height of spinous process

\section{Declarations}

\section{Acknowledgements}

There is no acknowledgment for the present study.

\section{Funding}

There is no funding for the present study.

\section{Availability of data and materials}

Available upon request from corresponding author. 


\section{Ethics approval and consent to participate}

This study was approved by the Ethical Committee of Iran University of Medical Sciences. Written informed consent was obtained from each participant. All authors read and approved the study.

\section{Author's contribution}

Conceived and designed the experiments: RSM \& AA. Performed the experiments: AM \& AA. Analysed the data: OM \& AM. Wrote the paper: OM, RSM. All authors read and approved the final manuscript.

\section{Consent for publication}

Not applicable.

\section{Competing interests}

The authors declare that they have no competing interests.

\section{References}

1. Gama I, Navega D, Cunha E. Sex estimation using the second cervical vertebra: a morphometric analysis in a documented Portuguese skeletal sample. Int J Legal Med. 2015;129(2):365-72.

2. Krishan K, Chatterjee PM, Kanchan T, Kaur S, Baryah N, Singh R. A review of sex estimation techniques during examination of skeletal remains in forensic anthropology casework. Forensic Sci Int. 2016;261:165. e1-. e8.

3. Marlow EJ, Pastor RF. Sex determination using the second cervical vertebra-a test of the method. J Forensic Sci. 2011;56(1):165-9.

4. Rozendaal AS. Estimating sex from the seven cervical vertebrae: an analysis of White European skeletal populations. 2016.

5. Noorian Zavareh F, Ameri M, Kordrostami R, Dadashzade N. The role of gender dimorphism on the relative length of fingers and the determination of the gender of the Iranian population: brief report. Tehran University Medical Journal TUMS Publications. 2017;75(8):616-20.

6. SOLTANI S, AMERI M, AGHAKHANI K. GHORBANI S. Evaluation of Greater Sciatic Notch Parameters in Sex Determination of Hip Bone by Three-Dimensional CT Images. Journal of Clinical \& Diagnostic Research. 2018;12(9).

7. El Dine FMB, El Shafei MM. Sex determination using anthropometric measurements from multi-slice computed tomography of the 12th thoracic and the first lumbar vertebrae among adult Egyptians. Egyptian Journal of Forensic Sciences. 2015;5(3):82-9.

8. Ubelaker DH, DeGaglia CM. Population variation in skeletal sexual dimorphism. Forensic Sci Int. 2017;278:407. e1-. e7. 
9. Mostafa EM, El-Elemi AH, El-Beblawy MA, Dawood AE-WA. Adult sex identification using digital radiographs of the proximal epiphysis of the femur at Suez Canal University Hospital in Ismailia, Egypt. Egyptian Journal of Forensic Sciences. 2012;2(3):81-8.

10. Holman DJ, Bennett KA. Determination of sex from arm bone measurements. Am J Phys Anthropol. 1991;84(4):421-6.

11. Moneim WMA, Hady RHA, Maaboud RMA, Fathy HM, Hamed AM. Identification of sex depending on radiological examination of foot and patella. Am J Forensic Med Pathol. 2008;29(2):136-40.

12. Abd-elaleem SA-e, Abd-elhameed $M$, Ewis $A A$. -e. Talus measurements as a diagnostic tool for sexual dimorphism in Egyptian population. J Forensic Leg Med. 2012;19(2):70-6.

13. Zakaria MS, Mohammed AH, Habib SR, Hanna MM, Fahiem AL. Calcaneus radiograph as a diagnostic tool for sexual dimorphism in Egyptians. J Forensic Leg Med. 2010;17(7):378-82.

14. Eshak GA, Ahmed HM, Gawad EAA. Gender determination from hand bones length and volume using multidetector computed tomography: a study in Egyptian people. J Forensic Leg Med. 2011;18(6):246-52.

15. Papaioannou VA, Kranioti EF, Joveneaux P, Nathena D, Michalodimitrakis M. Sexual dimorphism of the scapula and the clavicle in a contemporary Greek population: applications in forensic identification. Forensic Sci Int. 2012;217(1-3):231. e1-. e7.

16. Dabbs GR, Moore-Jansen PH. A method for estimating sex using metric analysis of the scapula. J Forensic Sci. 2010;55(1):149-52.

17. Singh J, Pathak R, Singh D. Morphometric sex determination from various sternal widths of Northwest Indian sternums collected from autopsy cadavers: a comparison of sexing methods. Egyptian Journal of Forensic Sciences. 2012;2(1):18-28.

18. Wescott DJ. Sex variation in the second cervical vertebra. Journal of forensic science. 2000;45(2):462-6.

19. Yu SB, Lee UY, Kwak DS, Ahn YW, Jin CZ, Zhao J, et al. Determination of sex for the 12th thoracic vertebra by morphometry of three-dimensional reconstructed vertebral models. J Forensic Sci. 2008;53(3):620-5.

20. Marino EA. Sex estimation using the first cervical vertebra. Am J Phys Anthropol. 1995;97(2):12733.

21. Zheng WX, Cheng FB, Cheng KL, Tian Y, Lai Y, Zhang WS, et al. Sex assessment using measurements of the first lumbar vertebra. Forensic Sci Int. 2012;219(1-3):285. e1-. e5.

22. Hou WB, Cheng KL, Tian SY, Lu YQ, Han YY, Lai Y, et al. Metric method for sex determination based on the 12th thoracic vertebra in contemporary north-easterners in China. J Forensic Leg Med. 2012;19(3):137-43.

23. Bethard JD, Seet BL. Sex determination from the second cervical vertebra: a test of Wescott's method on a modern American sample. J Forensic Sci. 2013;58(1):101-3. 
24. Voisin MD. Sexual dimorphism in the 12th thoracic vertebra and its potential for sex estimation of human skeletal remains: Wichita State University; 2011.

25. Benazzi S, Bertelli P, Lippi B, Bedini E, Caudana R, Gruppioni G, et al. Virtual anthropology and forensic arts: the facial reconstruction of Ferrante Gonzaga. J Archaeol Sci. 2010;37(7):1572-8.

26. Kibii JM, Pan R, Tobias PV. Morphometric variations of the 7th cervical vertebrae of Zulu, White, and colored South Africans. Clinical Anatomy: The Official Journal of the American Association of Clinical Anatomists and the British Association of Clinical Anatomists. 2010;23(4):399-406.

27. Torimitsu S, Makino Y, Saitoh H, Sakuma A, Ishii N, Hayakawa M, et al. Stature estimation in Japanese cadavers based on the second cervical vertebra measured using multidetector computed tomography. Leg Med. 2015;17(3):145-9.

28. Parenteau CS, Wang NC, Zhang P, Caird MS, Wang SC. Quantification of pediatric and adult cervical vertebra-anatomical characteristics by age and gender for automotive application. Traffic Inj Prev. 2014;15(6):572-82.

\section{Supplementary Files}

This is a list of supplementary files associated with this preprint. Click to download.

- Supplement.docx 